\title{
Trichloroethylene: A Cardiac Teratogen in Developing Chick Embryos
}

\author{
CLEO P. LOEBER, ${ }^{\prime}$ MARY J. C. HENDRIX, STEVEN DIEZ DE PINOS, AND \\ STANLEY J. GOLDBERG
}

Departments of Pediatrics and Anatomy, University of Arizona, Health Sciences Center, Tucson, Arizona 85724

\begin{abstract}
Prior studies have evaluated the teratogenicity of TCE, a contaminant of drinking water. However, none specifically examined effects of TCE on cardiogenesis. The purpose of this study was to determine if TCE is a cardiac teratogen in early embryogenesis in an avian model. Fertile White Leghorn chicken eggs were incubated under standard conditions. At stage 6, 12, 18, or 23, TCE, in concentrations of 5 to $25 \mu \mathrm{M}$ ( 2 to $28 \mu \mathrm{g} / \mathrm{g}$ body weight) was injected into the air space of the egg $(\mathrm{vol}=0.03 \mathrm{ml})$. Mineral oil and saline served as control solutions. For this double-blinded study, solutions were coded and remained so until all observations were made and recorded. Embryonic hearts $(n=1055)$ were examined at stage 29,34 , or 44. Gross examination was performed, followed by microdissection. Cardiac malformations were found in $7.3 \%$ of TCE-treated hearts, compared to $2.3 \%$ of saline controls $(p<0.01)$, and $1.5 \%$ of mineral oil controls $(p<0.001)$. No significant difference in incidence of malformations was found when comparing saline and mineral oil controls. Cardiac defects include septal defects, cor biloculare, conotruncal abnormalities, atrioventricular canal defects, and abnormal cardiac muscle. These data demonstrate that TCE is a cardiac teratogen in an avian model. (Pediatr Res 24: $740-744,1988$ )
\end{abstract}

Abbreviations

TCE, trichloroethylene

ECM, extracellular matrix

SEM, scanning electron microscopy

TCE, an unsaturated chlorinated hydrocarbon with the molecular structure $\mathrm{C}_{2} \mathrm{HCl}_{3}$, has been used as an anesthetic, in food processing, and as a metal degreaser. Although a 1977 Federal Drug Administration ruling prohibited further use of TCE in food processing (1), TCE is still found in small amounts in some foods. Additionally, TCE has been found to be a contaminant of drinking water in many cities in the United States. Studies investigating acute effects of TCE toxicity as well as its mutagenic and carcinogenic qualities have been extensively reported and will not be summarized here. Few studies, however, have investigated the teratogenicity of TCE; none have adequately examined the heart. Bross et al. (2) and Elovaara et al. (3) examined effects of TCE on chick embryos; both found increased mortality and malformation in TCE-treated embryos compared to con-

Received May 10, 1988; accepted August 12, 1988.

Correspondence Cleo Loeber, M.D., Department of Pediatrics, University of Iowa, Iowa City, IA 52242.

${ }^{1}$ Supported by American Heart Association, Arizona Affiliate Grant-in-Aid Award \#27, and an Upjohn Educational Grant. trols. However, neither study specifically examined the heart. Three additional reports concentrated on effects of maternally inhaled TCE on rat and mouse fetuses (4-6). None of these studies emphasized visceral examination. Therefore, it is uncertain if TCE is a cardiac teratogen. The purpose of this investigation was to evaluate the possibility of TCE-associated cardiac teratogenicity during early embryogenesis in a well established avian model.

\section{MATERIALS AND METHODS}

Fertile White Leghorn chick eggs $(n=1464)$ were obtained from the University of Arizona Poultry Farm at stage zero. A rotating incubator was maintained at $38.5^{\circ} \mathrm{C}$ with $70 \%$ humidity. Experimental and control groups each consisted of 732 eggs; controls were divided equally between saline and mineral oil groups. Mineral oil was included as a control since it was used as the solvent for TCE. Eggs were candled to ascertain the presence and location of the embryo. The position of the embryo in the egg was marked on the shell. To prevent excessive removal of the protective mucin coating, only this small portion of the eggshell was cleansed with $70 \%$ ethanol. To prevent bacterial contamination, the remainder of the processing was conducted in a laminar flow hood. A Dremel drill equipped with a silicon carbide grinding bit was used to make a small hole (leaving the membrane intact) in the shell at the location of the embryo. Using a sterile syringe and 28 -gauge needle, the membrane was perforated and $0.03 \mathrm{ml}$ of solution was injected. Injections were performed at stage $6,12,18$, or 23 . After injection, the hole was covered with tape and the egg returned to the incubator.

Solutions included sterile normal saline, mineral oil, and TCE. TCE (99+\% spectrophotometric grade; Aldrich Chemical Company Inc., Milwaukee, WI), mol wt 131, was dissolved in mineral oil. All solutions were coded to allow a double-blinded study. Five concentrations of TCE ranged from 5 to $25 \mu \mathrm{M}$ in increments of $5 \mu \mathrm{M}$. Based on embryonic weights by Elovaara (3), this is a dosage range of 2 to $82 \mu \mathrm{g} / \mathrm{g}$ of body weight. The amount of TCE absorbed by the embryo was measured by gas chromatographic technique. Because TCE is a volatile, light-sensitive substance, it was prepared and stored in air-free amber-colored containers to ensure that calculated concentrations of TCE remained constant and predictable. Other solutions were stored in a similar manner. Decoding of solutions was accomplished after all hearts were completely processed and all lesions were identified.

Embryos were examined at stages 29, 34, or 44 according to criteria of Hamburger and Hamilton (7). The embryo was placed on its right side under a dissecting microscope. The posterior cardinal vein was located and, with a needle and syringe, Tyrode's solution was injected until blood was completely flushed from the heart. The heart was then fixed in an expanded state with $3 \%$ glutaraldehyde and refrigerated for $24 \mathrm{~h}$. 
After fixation, hearts were placed in Sorensen's buffer, $\mathrm{pH} 7.5$, and then examined using a Zeiss dissecting microscope. An initial external examination was performed, followed by microdissection. Initially, a left parasagittal cut was made to allow evaluation of the atrial septum, mitral valve, ventricular septum, left ventricular outflow tract, and great vessel alignment. This cut was accomplished in all specimens. The second cut, performed on stage 34 and 44 specimens, was an anterior coronal cut used to evaluate the right ventricular outflow tract. This was followed by a deeper coronal cut to further evaluate the left ventricular outflow tract, aortic valve, ascending aorta, and coronary arteries. The final cut, a right parasagittal, was used to evaluate the rightsided atrioventricular connection, and was accomplished in stage 34 and 44 specimens.

All cardiac developmental abnormalities were recorded and photographed. Dissected hearts were then prepared for SEM. Dehydration was accomplished using a series of ascending grades of ethanol with final drying achieved according to the critical point drying method of Anderson (8). Hearts were then mounted on aluminum stubs and coated with gold-palladium to insure electrical conductivity. All specimens were examined with an Eec-Autoscan SEM, operating at an accelerating voltage of 20 $\mathrm{kv}$.

\section{RESULTS}

After accounting for infertility (12\%) and embryonic death (16\%), 1055 hearts were available for cardiac examination. Gas chromatography demonstrated that only $0.2 \%$ of the TCE delivered was absorbed by the embryo. Cardiac malformations were found in $7.3 \%$ of TCE-treated hearts compared to $2.3 \%$ of saline controls $(p<0.01)$, and $1.5 \%$ of mineral oil controls $(p<0.001)$ (Fig. 1). No significant difference in percentage affected was found between saline and mineral oil controls $(p<0.5)$ (Fig. 1). The incidence of cardiac malformation did not vary with the day of injection $(p<0.5)$. The greatest percentage occurrence of cardiac malformations was observed with $20 \mu \mathrm{M}$ TCE $(21 \%$ compared to $2.3 \%$ to $7.2 \%$ for the other groups; $p<0.001$ ) (Table 1). The type of malformation did not differ significantly between the groups. A complete listing of cardiac malformations observed in TCE-treated embryos and controls is given in Table 1 .

Morphologic analyses of stage 34 and 44 control and TCEtreated hearts reveal normal development in the majority of control specimens (Fig. 2a). Cardiac malformations noted in the TCE-treated embryos include cor biloculare (Fig. $2 b$ ), atrioventricular canal defects (Fig. $2 c$ and $d$ ), and malposed truncus arteriosus (Fig. $3 a$ ). Scanning electron microscopic observations of a representative heart with a malposed truncus arteriosus shows a ventricular septal defect (Fig. $3 b$ ). Figure $3 c$ demonstrates

\section{$\%$ CARDIAC 购ALFOROMATUONS}

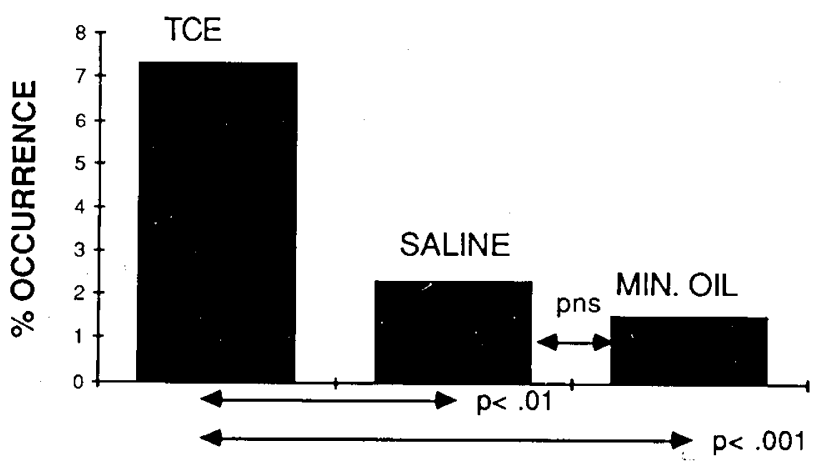

Fig. 1. Graph demonstrating the percentage occurrence of cardiac malformations in TCE and control groups ( $\mathrm{min}$ oil = mineral oil).
Table 1. Cardiac malformations in chick embryos injected with TCE*

\begin{tabular}{|c|c|c|c|c|c|c|c|c|}
\hline \multirow[b]{2}{*}{ Cardiac malformations } & \multicolumn{6}{|c|}{ Concentration of TCE $(\mu \mathrm{M})$} & \multirow[b]{2}{*}{ Saline } & \multirow[b]{2}{*}{ Mineral oil } \\
\hline & 5 & 10 & 152 & 20 & 25 & Total & & \\
\hline Tricuspid atresia & & & 1 & & & 1 & & \\
\hline Atrioventricular canal & & 2 & 1 & 1 & & 4 & 1 & \\
\hline $\begin{array}{l}\text { Conotruncal abnor- } \\
\text { mality }\end{array}$ & 1 & & & & & 1 & & \\
\hline Cor biloculare & & & 1 & 1 & & 2 & & \\
\hline Primum ASD & & & 1 & & & 1 & 1 & \\
\hline Secundum ASD & & 1 & 1 & 3 & 3 & 8 & 1 & 2 \\
\hline VSD-membranous & & 1 & & 1 & & 2 & & \\
\hline VSD-muscular & & 1 & & & 1 & 2 & & \\
\hline Cor triatratum & 1 & & & & & 1 & & \\
\hline $\begin{array}{l}\text { Single ventricle with } \\
\text { outlet chamber }\end{array}$ & & & 1 & 2 & & 3 & & \\
\hline $\begin{array}{l}\text { Malposed truncus ar- } \\
\text { teriosus }\end{array}$ & & 1 & 1 & 3 & 1 & 6 & 3 & \\
\hline $\begin{array}{l}\text { Abnormal cardiac } \\
\text { muscle }\end{array}$ & & 1 & 2 & 4 & & 7 & & \\
\hline Grossly abnormal & & 1 & 1 & 3 & & 5 & 1 & 1 \\
\hline Hypoplastic ventricle & 1 & & & 1 & & 2 & & \\
\hline Primitive heart & & & 1 & 1 & & 2 & & \\
\hline Total hearts examined & 128 & $91 \mathrm{~s}$ & 978 & 8612 & & 5222 & 267 & 266 \\
\hline $\begin{array}{l}\text { Total No. malformed } \\
\text { hearts }\end{array}$ & 3 & 6 & 71 & 18 & 4 & 38 & 6 & 4 \\
\hline $\begin{array}{l}\% \text { with malformed } \\
\text { hearts }\end{array}$ & 2.3 & 6.6 & 7.22 & & 3.3 & 7.3 & 2.3 & 1.5 \\
\hline
\end{tabular}

* TCE-treated embryos had significantly greater number of cardiac malformations compared to saline controls $(p<0.01)$ and mineral oil $(p<0.001)$ controls. There was no significant difference between saline and mineral oil controls $(p=0.5)$. A significantly greater number of cardiac malformations occurred in the $20 \mu \mathrm{M}$ group compared to other treatment groups $(p<0.001)$. ASD, atrial septal defect; VSD, ventricular septal defect.

a normal atrial septum in a control stage 44 chick embryo as compared with a secundum atrial septal defect seen in a stage 44 TCE-treated embryo (Fig. 3d).

In addition to an increased incidence of cardiac malformations, TCE was also associated with increased embryonic death; $7.4 \%$ compared to $3.9 \%$ of saline $(p<0.001)$ and $4.7 \%$ of mineral oil $(p<0.001)$ controls (Fig. 4). This rate did not differ significantly with the concentration of TCE $(p=0.4)$.

\section{DISCUSSION}

The most significant finding of this study was the demonstration that TCE is clearly associated with abnormal cardiac morphogenesis in an avian model. This is especially important as TCE appears to be a common contaminant in drinking water. According to analysis by the Arizona State Health Department, the level of TCE in Tucson drinking water ranged from 6.9 to 200 parts per billion. The Environmental Protection Agency recommends $<5$ parts per billion. A $20-\mu \mathrm{M}$ concentration is equal to approximately 200 parts per million. With only $0.2 \%$ of delivered TCE absorbed by the embryo and a single exposure, our dosages are probably significantly less than environmental exposures.

The majority of TCE-associated cardiac defects detected in this study fit into three of six categories of pathogenetic mechanism as proposed by Clark (9). One possibility for the lack of a single pathogenetic mechanism is that TCE exerts a generalized toxic, rather than specific teratogenic, effect. However, another possibility, which is supported by recent experimental evidence, is that this classification scheme may need to be revised. The 

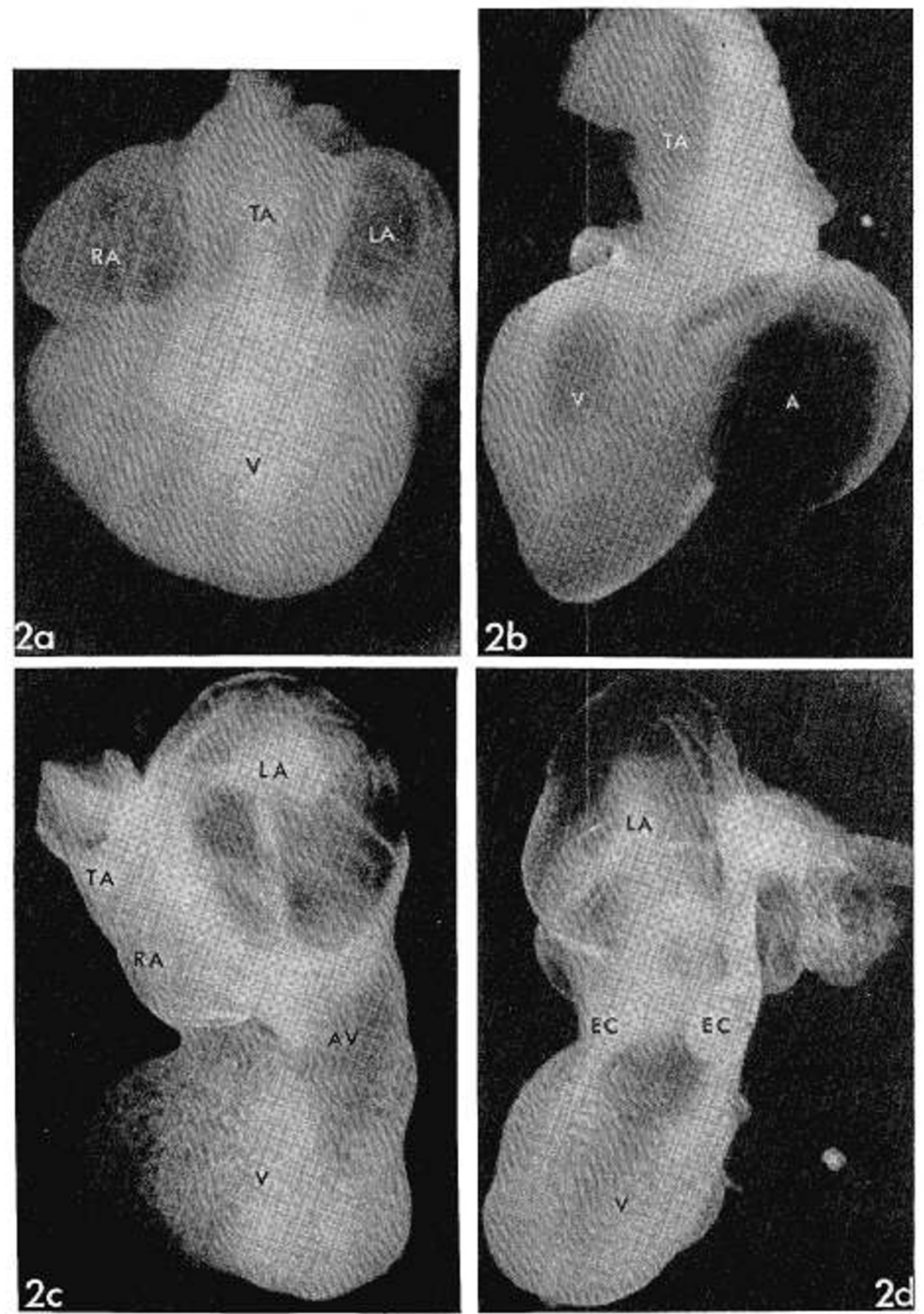

Fig. 2. Microscopic light micrographs (LM) and SEM of stage 34 chick embryonic hearts, both normal (control) and TCE-treated (experimental). a: LM anterior view of a normal stage 34 control chick embryonic heart. RA, right atrium; LA, left atrium; TA, truncus arteriosus; $\mathrm{V}$, ventricular region. $b: \mathrm{LM}$ anterior view of cor biloculare in a $20-\mu \mathrm{M}$ TCE-treated heart. $\mathrm{A}$, atrial chamber; $\mathrm{V}$, ventricular chamber; TA, truncus arteriosus. $c$ : LM left lateral oblique view of a malformed 15- $\mu \mathrm{M}$ TCE-treated heart with an elongated atrioventricular region (see $d$ ). $\mathrm{TA}$, truncus arteriosus; $\mathrm{AV}$, atrioventricular region. $d$ : LM left lateral view of the heart seen in $c$. The large atrioventricular canal defect is obvious. EC, endocardial cushion.

three categories of lesions detected in this study were: 1 ) ectomesenchymal tissue migration abnormalities, 2) ECM abnormalities and, 3) cell death abnormalities. Substantial experimental evidence now exists to support that ectomesenchymal cell migration is dependent upon a cell-substrate interaction between cell surface receptors and components of the ECM (10). Thus, it is likely that lesions in category 1 and 2 are of similar pathogenetic origin. Pexieder has presented substantial evidence supporting the role of cell death in both normal and abnormal cardiac morphogenesis (11). Recent evidence suggests that cellECM interactions may play an important role in events that are currently or were previously thought to be mediated by cell death
$(12,13)$. Thus, there is increasing evidence to suggest that cellECM interactions are important in cell growth, development, and migration and may dictate a revision of the categories of pathogenetic mechanism as proposed by Clark $(9,10,12-16)$. Although a definitive mechanism of action of TCE cannot be stated from these data, they are suggestive of abnormal cell-ECM interactions and may provide the groundwork for future investigation in this direction.

No other investigators have studied the cardiac teratogenicity of TCE. Additionally, none of the studies have been doubleblinded, and each study has had additional significant limitations. Bross et al. (2), and Elovaara et al. (3) did not examine the 

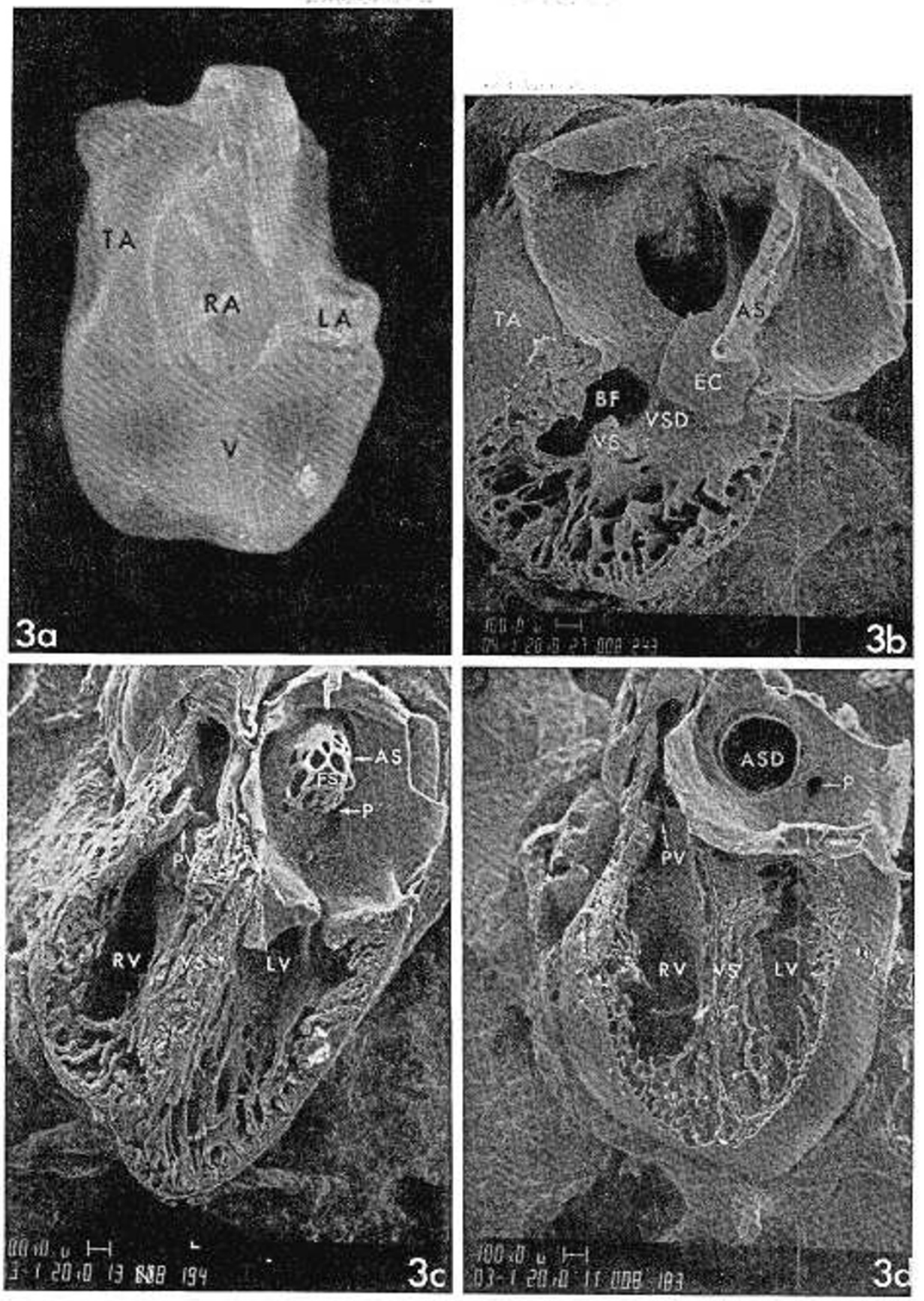

Fig. 3. $a$ : LM anterior view of a 20- $\mu \mathrm{M}$ TCE-treated heart with a malposed truncus arteriosus (see $b$ ). b: Left lateral view of the heart in $a$, as seen by scanning electron microscopy. Note the large ventricular septal defect in the membranous position. AS, atrial septum; VSD, ventricular septal defect; VS, ventricular septum; BF, bulboventricular foramen. $c$ : SEM left lateral view of a normal stage 34 control heart. Note the well established meshwork of the bulging atrial septum. PV, pulmonary valve; FS, foramina secundum; P, pulmonary vein; RV, right ventricle; LV left

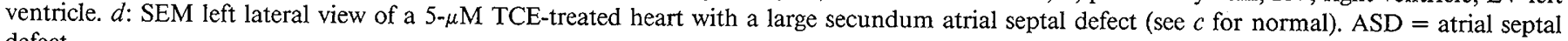
defect.

heart. Nor did they include comment on the prevention or volatilization of TCE into the air, and degradation of TCE by light. Both of these methodologic exclusions would have resulted in unreliable and unpredictable concentrations of TCE solutions. For studies of inhaled TCE, these methodologic measures (volatilization and light degradation) were not pertinent. Healy et al. (4) removed viscera of 187 rat fetuses and conducted gross examinations; no defects were found. However, macroscopic examination is inadequate for detecting cardiac malformations. Schwetz et al. (5) performed microscopic examinations of sagittal sections of 30 TCE-exposed rat and mouse fetuses; the heart is not mentioned as an organ examined.
Limitations of our study included our inability to detect several cardiac lesions. Semilunar and atrioventricular valve stenoses, unless associated with grossly malformed valves, would not have been detected in our model. Detection of coarctation of the aorta was not pursued because of the difficulty in following the aorta beyond the proximal transverse arch. These limitations should result in underestimation of TCE-associated cardiac malformations. TCE is associated with an increased rate of embryonic death. Because of tissue changes that occur with death, we were unable to evaluate hearts of dead embryos. Yet cardiac malformation may have been present. This would have resulted in an underestimation of TCE-associated cardiac malformations. 
$\%$ DEATR]

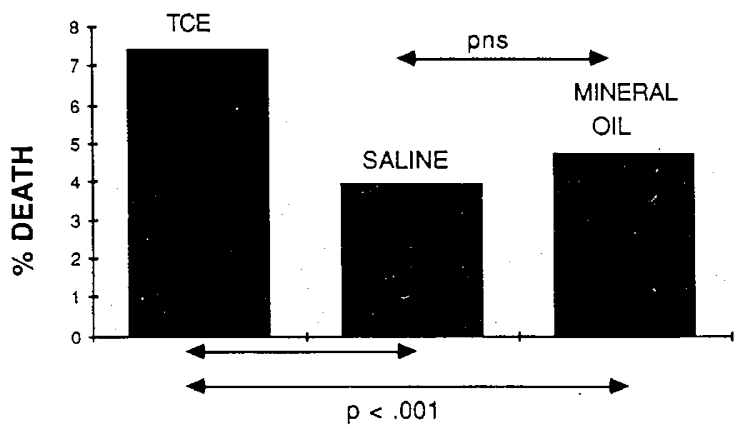

Fig. 4. Percentage occurrence of death for TCE, and saline and mineral oil control groups. TCE was associated with significantly greater percentage of death compared to saline $(p<0.001)$ and mineral oil $(p$ $<0.001)$ controls. pns, $p$ value not significant.

Our study placed special emphasis on the critical handling of TCE due to its volatile, light sensitive, and evaporative nature. This is of paramount importance in the execution and repetition of statistically significant results in such a study. We are unable to explain why the greatest effect of TCE occurred with the 20 $\mu \mathrm{M}$ concentration. All concentrations of TCE were prepared at the start of the study and stored under optimal conditions. Although some variability in concentration may have occurred over time, it is unlikely that this accounted for difference in percent occurrence seen in the $20 \mu \mathrm{M}$ group. It was not due to an increased death rate for other concentrations making fewer hearts available for examination in other groups. Although the incidence of TCE-associated cardiac defects is significantly increased over controls, the percentage remains relatively low (7.3\%). Thus, other toxins with a greater incidence of teratogenic effects may be more suitable for studying mechanisms of teratogenesis. We have shown that the embryonated chick egg is an excellent model in which to evaluate the effects of a teratogen, such as TCE. In addition, several cardiac defects were created by the administration of TCE, which would allow one the oppor- tunity to study the progression of various malformations through a narrow window of time.

\section{REFERENCES}

1. 1980 International Agency for Research on Cancer: IARC Monographs on the Evaluation of Carcinogenic Risk. vol 20

2. Bross G, DiFranceisco D, Desmond ME 1983 The effects of low dosages of trichloroethylene on chick development. Toxicology 28:283-294

3. Elovaara G, Hemminki K, Vainio H 1979 Effects of methylene chloride, trichloroethane, trichloroethylene, tetrachloroethylene and toluene on the development of chick embryos. Toxicology 12:111-119

4. Healy TEJ, Poole TR, Hopper A 1982 Rat fetal development and maternal exposure of trichloroethylene $100 \mathrm{ppm}$. Br J Anaesth 54:337-341

5. Schwetz BA, Leong BKJ, Gehring PJ 1975 The effect of maternally inhaled trichloroethylene, perchloroethylene, methyl chloroform, and methylene chloride on embryonal and fetal development in mice and rats. Toxicol Appl Pharmacol 32:84-96

6. Dorfmueller MA, Henne SP, York RG, Bornscheir RL, Manson JM 1979 Evaluation of teratogenicity and behavioral toxicity with inhalation exposure of maternal rats to trichloroethylene. Toxicology 14:153-166

7. Hamilton HH 1952 Lillie's Development of the Chick, 3rd ed. Henry Holt \& $\mathrm{Co}$, New York

8. Anderson TF 1951 Techniques for the preservation of three-dimensional structure in preparing specimens for the electron microscope. Trans NY Acad Sci 13:130-133

9. Clark EB 1988 Growth, Morphogenesis and Function: The Dynamics of Heart Development. In: Moller J, Neal WA, Lock JE (eds) Fetal, Neonatal and Infant Heart Disease. Appleton-Century-Croft, New York, in press

10. Hay ED 1981 Cell Biology of Extracellular Matrix. Plenum Press, New York, 1981

11. Pexieder $\Upsilon 1975$ Cell death in morphogensis and teratogenesis of the heart. Adv Anat Embryol Cell Biol 51:1-100

12. Donahoe PC, Budzik GP, Trelsted RL, Schwartz BR, Fallat ME, Hutson JM 1984 Molecular Dissection of Mullerian Duct Regression. In: Trelsted RL (ed) The Role of Extracellular Matrix in Development. Alan R Liss, Inc, New York, pp 573-595

13. Fitchett JE, Hay ED 1987 Medial edge epithelium (MEE) transforms to mesenchyme after embryonic palatal shelves fuse. J Cell Biol 105:256a(abstr)

14. Heine UI, Munoz EF, Flanders KC, Ellingsworth LR, Lam HYP, Thompson NL, Roberts AB, Sporn MB 1987 The Role of Transforming Growth Factorbeta in the Development of the Mouse Embryo. J Cell Biol 105:2861-2876

15. Roberts AB, Flanders KC, Kondaiah P, Thompson NL, Van ObberghenSchilling E, Wakefield L, Rossi P, de Crombrugghe B, Heine U, Sporne MB 1988 Transforming growth factor Beta: Biochemistry and roles in embryogenesis, tissue repair and remodeling, and carcinogenesis. Rec Prog in Horm Res, vol 43, in press

16. Sporn MB, Roberts AB, Wakefield L, de Crombrugghe B 1987 Some recent advances in the chemistry and biology of transforming growth factor-beta. $\mathbf{J}$ Cell Biol 105:1039-1045 